\title{
One-Dimensional Constitutive Model of Shape Memory Alloy with an Empirical Kinetics Equation
}

\author{
Lei Li, ${ }^{1,2}$ Qingbin Li, ${ }^{1}$ and Fan Zhang ${ }^{3}$ \\ ${ }^{1}$ State Key Laboratory of Hydroscience and Engineering, Tsinghua University, Beijing 100084, China \\ ${ }^{2}$ China Three Gorges Corporation, Yichang, Hubei Province 443133, China \\ ${ }^{3}$ Department of Transportation of Henan Province, Zhengzhou 450052, China
}

Correspondence should be addressed to Qingbin Li, qingbinli@tsinghua.edu.cn

Received 8 November 2010; Accepted 11 January 2011

Academic Editor: D. H. Ping

Copyright (C) 2011 Lei Li et al. This is an open access article distributed under the Creative Commons Attribution License, which permits unrestricted use, distribution, and reproduction in any medium, provided the original work is properly cited.

\begin{abstract}
Characteristics of NiTi shape memory alloy (SMA) and its constitutive model with an empirical kinetics equation were investigated in this paper. Firstly, the transformation characters of the NiTi SMA were obtained through a differential scanning calorimetry (DSC) analysis technology, and the properties during incomplete and discontinuous transformation process and the effects of plastic deformation on the transformation were studied. The uniaxial tension, SME, and constrained recovery process of NiTi SMA were examined through an improved $10 \mathrm{KN}$ universal material testing machine. Experimental results indicated that the phase transformation characters and the mechanical properties could be affected by the loading process considerably, and the plastic deformation should be taken into account. To simulate the characteristics of NiTi SMA more effectively, a one-dimensional constitutive model derived from the internal variable approach with the consideration of the plastic deformation was constructed based on the DSC and the uniaxial tension experimental results, and a new simple empirical kinetics equation was presented, with the transformation temperature parameters redefined according to the DSC experiment evidence. Comparison between the numerical and experimental results indicated that this constitutive model could simulate the phase transformation characters, the uniaxial tension, SME, and the constrained recovery behavior of NiTi SMA well.
\end{abstract}

\section{Introduction}

Since the Shape Memory Effect (SME for short) was observed in $\mathrm{Cu}-\mathrm{Zn}$ alloy by Greninger and Mooradian [1], and in NiTi alloy by Buehler et al. [2], SMA (especially NiTi alloy) has been widely used as intelligent material for its particular characteristics, such as large load capacity, high recovery strain up to $8 \%$, excellent fatigue performance, variable elastic modulus with phase transformation, and especially the two main interesting properties, SME and Pseudoelasticity (PE) due to the diffusionless martensitic transformation, as discussed elsewhere [3-7].

To simulate these specific properties, many constitutive laws have been proposed, such as the phenomenological models [8-12], micromechanics models [13, 14], 3D model for polycrystalline SMA based on microplane theory [15], and so forth. Among them, phenomenological models based on the internal variable method were the most popular used in the practical engineering. The mechanical constitutive equation was derived from the principles of thermodynamics, martensite fraction as an internal variable was used to represent the stage of the transformation, and an empirical kinetics equation was proposed to describe this transformation governed by temperature and stress. The major difference of these models was its specific kinetics equation.

The first phenomenological model was derived by Tanaka and Nagaki [8] from the first and second laws of thermodynamics and can be written as

$$
\sigma=\rho_{0} \frac{\partial \Phi}{\partial \varepsilon}=\sigma(\varepsilon, T, \xi)
$$

where $\sigma, \rho_{0}, \Phi, \varepsilon, T$, and $\xi$ represent the second PiolaKirchhoff stress, the density, Helmholtz free energy, Green strain, temperature and the martensite fraction, respectively. 
Equation (1) can be written by differential calculus as

$$
\dot{\sigma}=\frac{\partial \sigma}{\partial \varepsilon} \dot{\varepsilon}+\frac{\partial \sigma}{\partial T} \dot{T}+\frac{\partial \sigma}{\partial \xi} \dot{\xi}=D \dot{\varepsilon}+\Theta \dot{T}+\Omega \dot{\xi},
$$

where $D=\rho_{0}\left(\partial^{2} \Phi / \partial \varepsilon^{2}\right)$ is the modulus of the SMA materials, $\Theta=\rho_{0}\left(\partial^{2} \Phi /(\partial \varepsilon \partial T)\right)$ is related to the thermal coefficient of expansion, and $\Omega=\rho_{0}\left(\partial^{2} \Phi /(\partial \varepsilon \partial \xi)\right)$ can be regarded as the "transformation tensor".

The relationship between the martensite fraction, the temperature and the stress is expressed by an exponential kinetics equation as

$$
\xi_{M \rightarrow A}=\exp \left[a_{A}\left(T-A_{s}\right)+b_{A} \sigma\right]
$$

for the transformation from martensite to austenite, and

$$
\xi_{A \rightarrow M}=1-\exp \left[a_{M}\left(T-M_{s}\right)+b_{M} \sigma\right]
$$

for the transformation from austenite to martensite, where $a_{A}, a_{M}, b_{A}, b_{M}$ are the material constants related to the transformation temperature, $A_{s}$ and $M_{s}$ are the start temperatures of austenite transformation and the martensite, respectively.

Chen [10] simplified the constitutive model based on (2), material functions were assumed to be constants, and the constitutive relation can be written as

$$
\sigma-\sigma_{0}=D\left(\varepsilon-\varepsilon_{0}\right)+\Omega\left(\xi-\xi_{0}\right)+\Theta\left(T-T_{0}\right),
$$

where the subscript " 0 " indicates the initial conditions of the materials. Martensite fraction, as a function of stress and temperature during transformation, is represented by an empirically based cosine models as

$$
\xi_{M \rightarrow A}=\frac{\xi_{0}}{2} \cos \left[a_{A}\left(T-A_{s}\right)+b_{A} \sigma\right]+\frac{\xi_{0}}{2}
$$

for the transformation from martensite to austenite, and

$$
\xi_{A \rightarrow M}=\frac{1-\xi_{0}}{2} \cos \left[a_{M}\left(T-M_{f}\right)+b_{M} \sigma\right]+\frac{1+\xi_{0}}{2}
$$

for the transformation from austenite to martensite, where $\xi_{0}$ is the initial martensite fraction, $a_{A}, a_{M}, b_{A}, b_{M}$ are the material constants, $A_{s}$ is the start temperature of austenite transformation, $M_{f}$ is the finish temperature of martensite transformation.

Brinson [11] redefined the martensite fraction based on the micromechanics of SMA material as

$$
\xi=\xi_{S}+\xi_{T}
$$

where $\xi_{s}$ represents the fraction of the stress-induced martensite (or single-crystal martensite) and $\xi_{T}$ denotes the fraction of the temperature-induced martensite with multiple variants.

Young's modulus was assumed to be nonconstant from the experimental evidence as

$$
D(\varepsilon, \xi, T)=D(\xi)=D_{A}+\xi\left(D_{M}-D_{A}\right),
$$

where $D_{A}$ and $D_{M}$ are the Young's moduli of austenite and martensite.
The transformation tensor was also redefined as

$$
\Omega(\xi)=\Omega\left(\xi_{0}\right)+\left(\xi-\xi_{0}\right) \Omega^{\prime}\left(\xi_{0}\right) .
$$

Because of these improvements, phenomenological models based on the internal variable method could simulate the characteristics of SMA well, such as SME and PE, and have been used in some commercial program for its simple form, whereas, DSC experiment indicated that there were no apparent transformation start and finish temperatures. And additionally, for the SMA materials used as actuators in practical engineering, not only the stress but also the thermo load determined the transformation process simultaneously, especially the latter. In this paper, constitutive model was presented to simulate the characteristics of SMA materials for its practical utilization based on the former effort and the thermal and mechanical experiments. Transformation temperature parameters were redefined, a new simple empirical kinetics equation was presented, and a mechanical equation was developed to describe its mechanical character more directly.

\section{Experiments and Results}

\subsection{Thermodynamics Experiment}

2.1.1. Complete Transformation. The Ti-49.5 wt \% Ni in this research (binary, straight annealed) was one-way SMA. Its transformation property can be achieved through a DSC apparatus (type: Mettler Toledo DSC821e), as shown in Figure 1, the four transformation temperatures can be determined as: martensite transformation start and finish temperatures denoted by $M_{s}$ and $M_{f}$ are $33.8^{\circ} \mathrm{C}$ and $23.3^{\circ} \mathrm{C}$, austenite transformation start and finish ones $\left(A_{s}\right.$ and $\left.A_{f}\right)$ are $41.9^{\circ} \mathrm{C}$ and $59.6^{\circ} \mathrm{C}$, respectively. It should be noticed that these transformation start and finish temperatures were defined through the DSC diagram artificially, actually the transformation could take place slowly earlier than the transformation start temperature and remain unfinished after the transformation finish temperature, as shown in the experimental curve, thus the recovery forces induced by the transformation might increase or decrease beyond the transformation start and finish temperatures. Accordingly, a new series of parameters were adopted to describe this transformation character more realistically, where $T_{A}$ and $T_{M}$ denotes the temperatures corresponding to the peak points of the austenite and martensite transformations, $A$ and $M$ indicate the widths of the transformation peaks, $A \approx$ $\left(A_{f}-A_{s}\right) / 2 e$ and $M \approx\left(M_{s}-M_{f}\right) / 2 e$, and $e$ is the natural constant and equals to 2.71828 .

Subtracting the exothermic or the endothermic part of nonphase transformation process from the DSC curve (as seen in Figure 1), normalizing the heat absorbing and releasing capacities, and taking the absolute value, the variance ratio of martensite quality fraction versus temperature can be achieved, as shown in Figure 2.

Calculating the integral of the variance ratio of martensite quality fraction, the relationship of martensite quality fraction versus temperature during the martensite and 


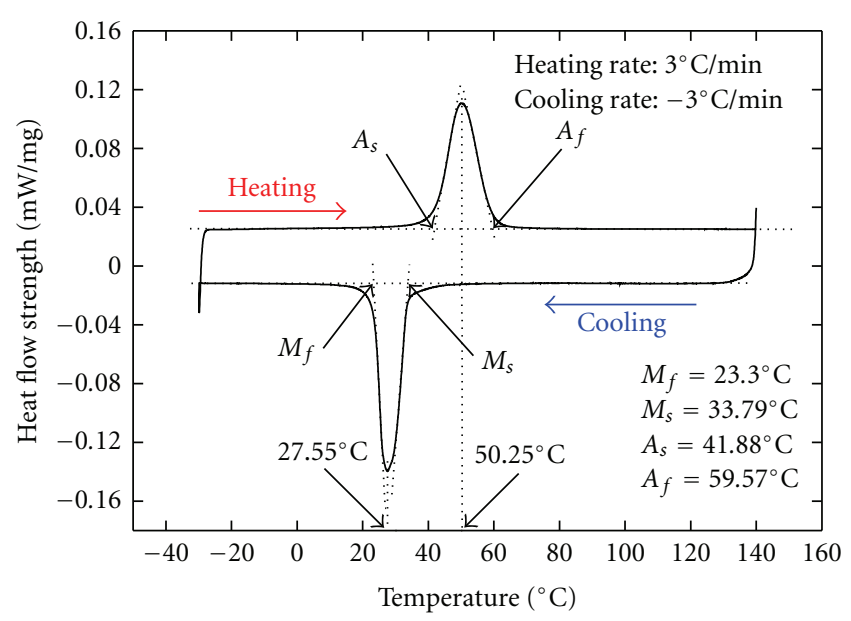

Figure 1: DSC diagram of SMA.

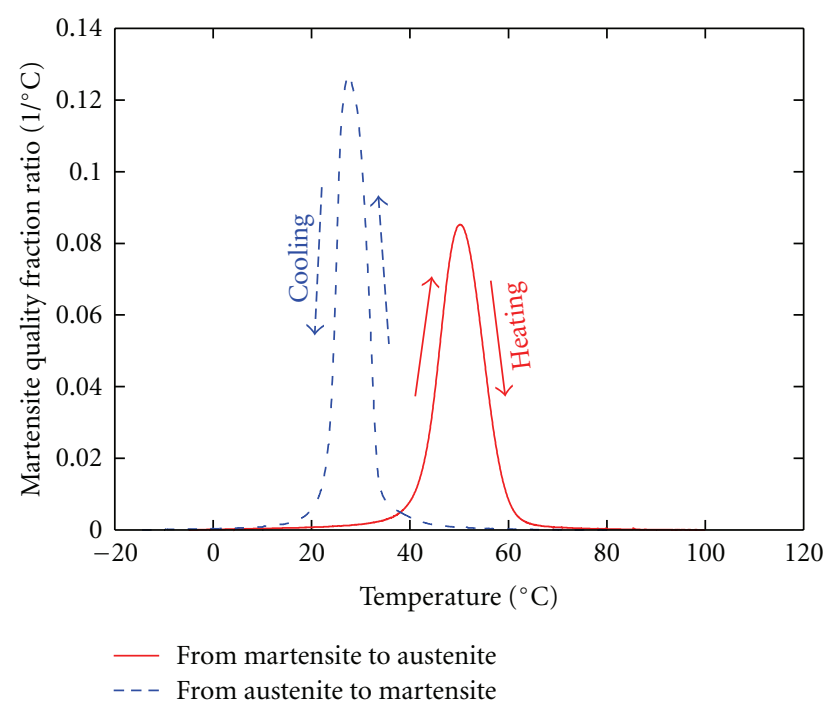

FIGURE 2: Variation rate of martensite quality fraction versus temperature.

austenite transformation process can be obtained, as shown in Figure 3.

2.1.2. Incomplete and Discontinuous Transformation. If the initial state is not the complete martensite or austenite, the phase transformation will be different.

When the initial state is pure austenite, cooling will induce the transformation from austenite to martensite, while at half of this transformation, heating will lead to the reverse transformation from the new generated martensite to austenite, the start and finish temperature and the shape of the peak are similar to the ones of the complete austenite transformation, but the peak value is smaller than the complete transformation one, as shown in Figure 4.

Similarly, when the initial state is pure martensite, heating will induce the transformation from martensite to austenite, while at half of the transformation, cooling will lead to the transformation from the new generated austenite

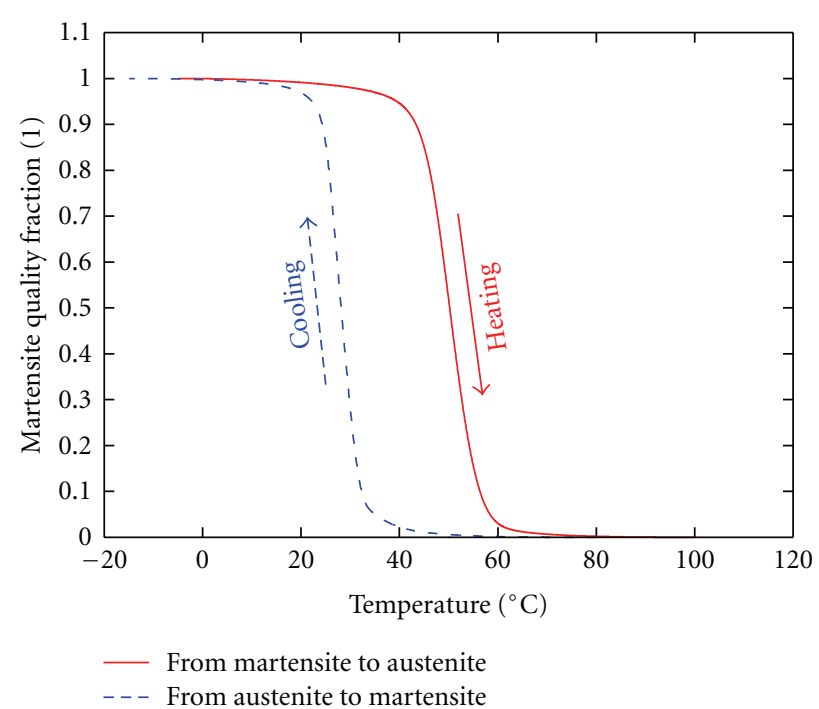

FIGURE 3: Variation of martensite quality fraction versus temperature.

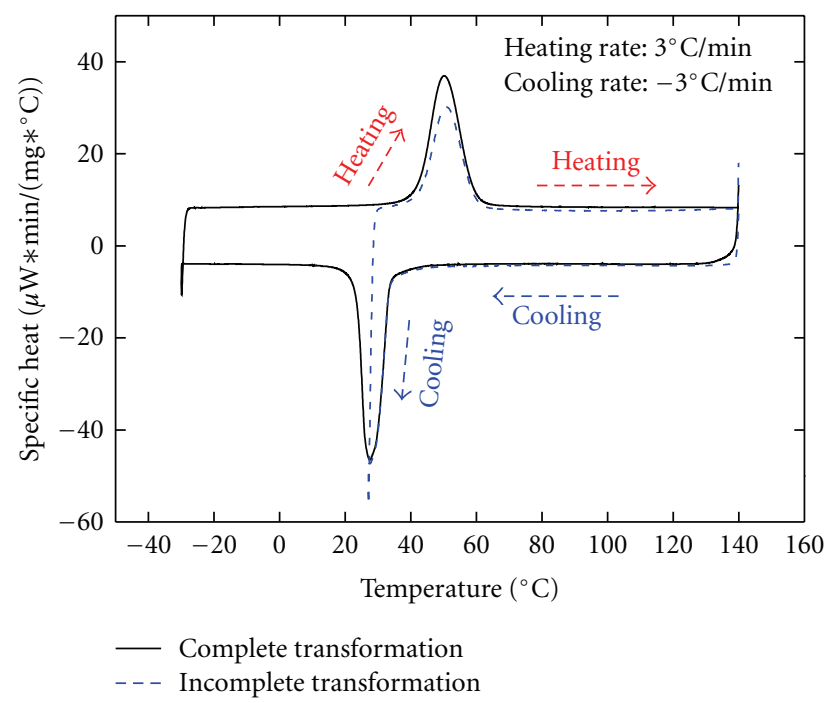

FIGURE 4: Incomplete transformation from martensite to austenite.

to martensite, the start and finish temperatures and the shape of the peak are similar to those of the complete martensite transformation, but the peak value becomes smaller than the complete transformation one, as shown in Figure 5.

These phenomena indicate that the intensity of the martensite and the austenite transformation is related to the initial austenite and the martensite quality fraction. Accordingly, it is assumed that the intensity of the martensite and the austenite transformation is proportional to the initial austenite and the martensite fraction.

For the transformation from austenite to martensite, that is, the cooling process, if the temperature rising with a narrow range does not induce the transformation from martensite to austenite, then this small heating will not impact the succedent transformation from austenite to martensite, as shown in Figure 6. 


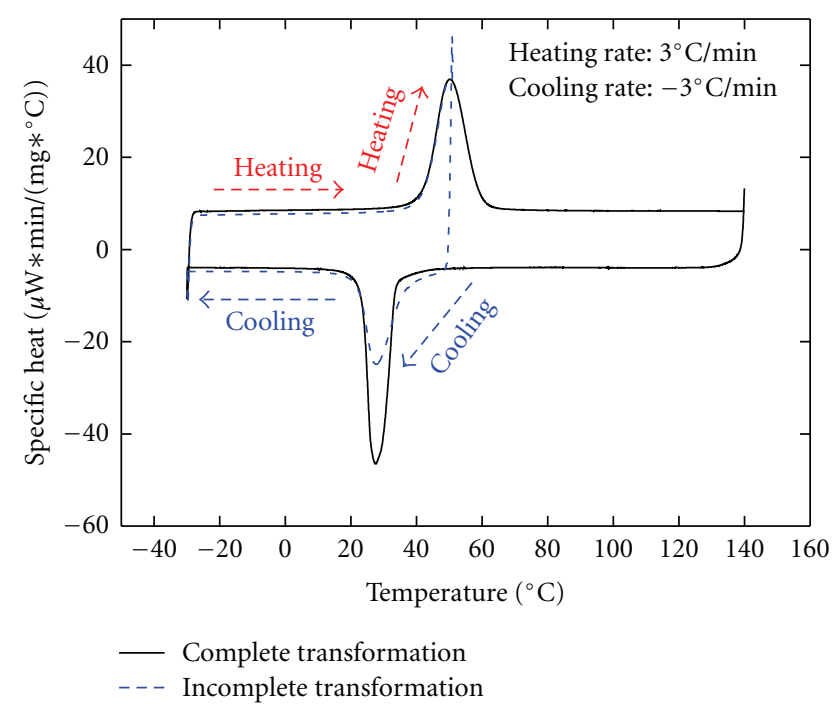

FIGURE 5: Incomplete transformation from austenite to martensite.

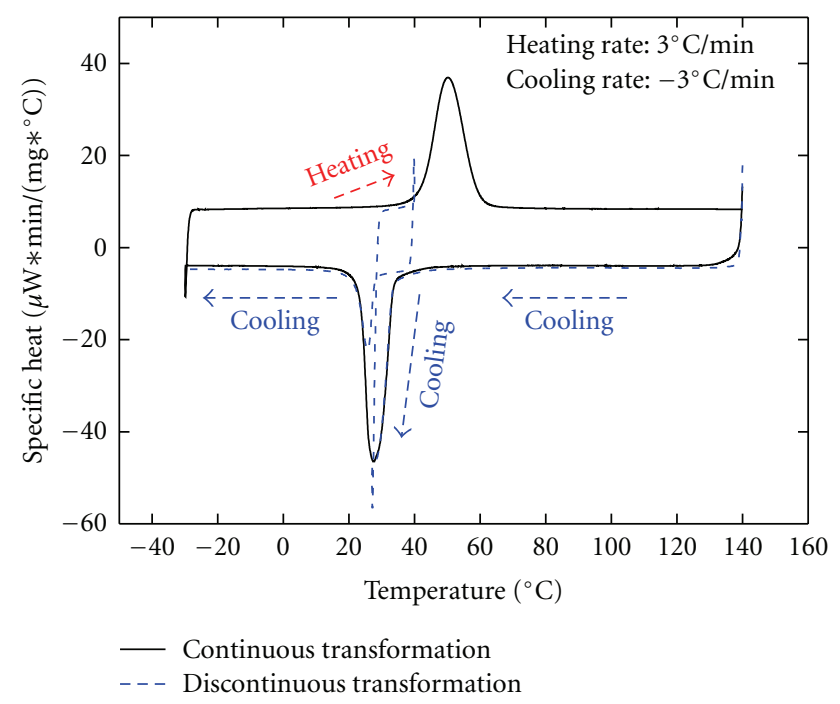

FIGURE 6: Discontinuous transformation from austenite to martensite.

Similarly, for the transformation from martensite to austenite, and so forth, the heating process, if a temperature dropping with a narrow range does not induce the transformation from austenite to martensite, then this small cooling will not impact the succedent transformation from martensite to austenite, as shown in Figure 7.

2.1.3. Influence of Plastic Deformation. Plastic deformation can also change the transformation properties of SMA materials. Stretch SMA to its strain limit, great plastic deformation will be induced, and the DSC experimental result can be achieved as shown in Figure 8. The temperatures corresponding to the peak points of the austenite and martensite transformations become higher in different degree, the width of the peak become wider, and the peak value become smaller than these before tension. This phenomenon comes

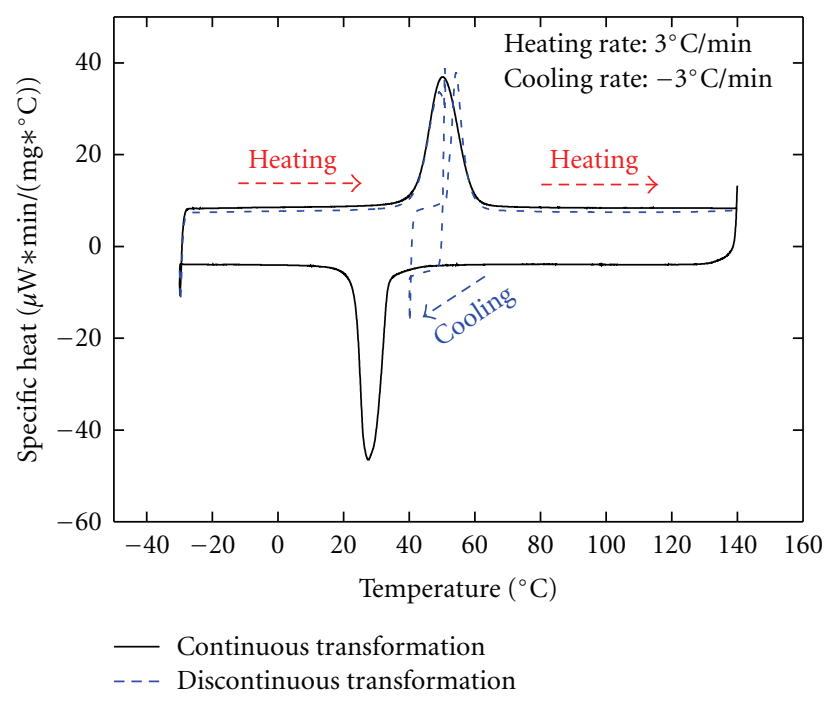

FIgURE 7: Discontinuous transformation from martensite to austenite.

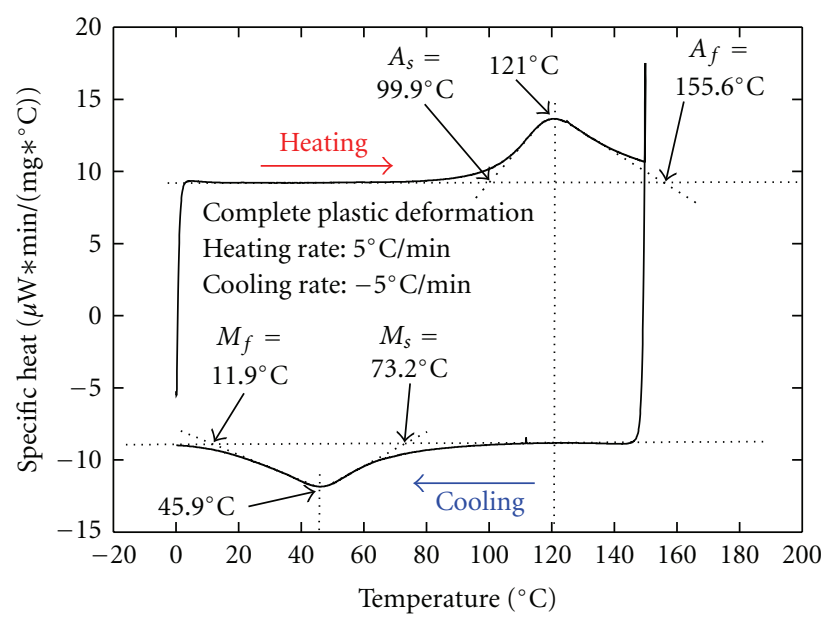

FIGURE 8: DSC analysis of plastic deformed SMA.

from the variation of the crystal structure and the internal stress induced by the plastic deformation. Actually, the transformation properties of the SMA crystal cell did not change, just the micro structure of SMA material varied.

2.2. Mechanics Experiment. Mechanics experiment was carried out to determine the material characteristics and parameters through a WDW-10 universal material test machine. The experimental equipment is shown in Figure 9. Pt100 platinum electric resistance temperature sensors were plastered on the SMA wire with silica gel to monitor its temperature, strain gauge was used to measure its strain, load applied on the SMA wire, environment temperature, current intensity, and the voltage of SMA wire between the two points of the strain gauge were also monitored at the same time, all these signals were acquired through a 16channel dynamic data acquisition system. 


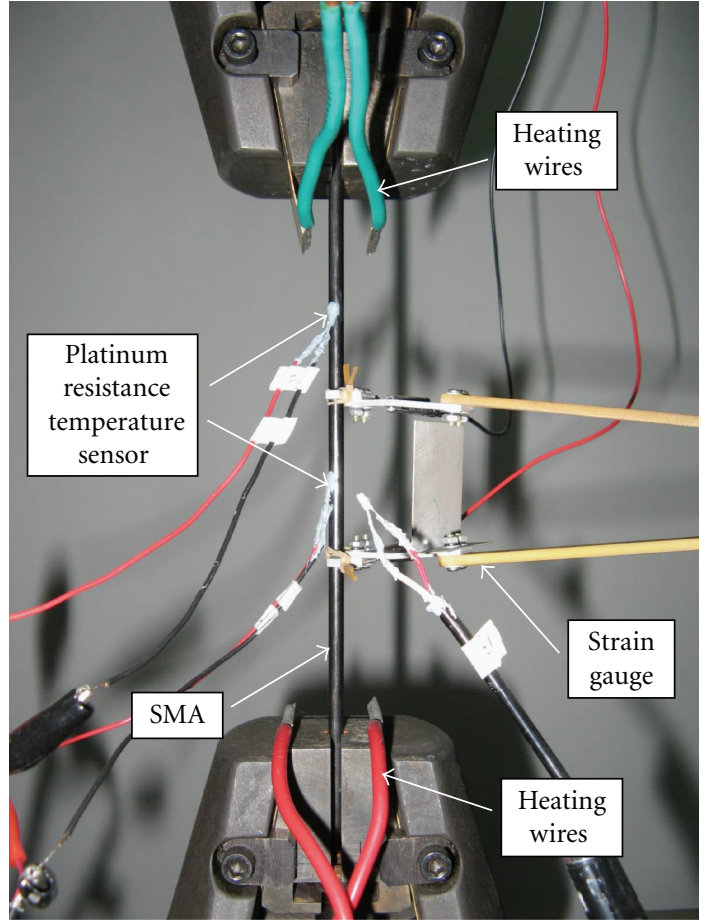

FIGURE 9: Uniaxial tension test equipment.

2.2.1. Uniaxial Tension Test. The first test was made with constant ambient temperature. SMA wire samples were heated by boiled water firstly, and then cooled by ice water, thus the initial state of the samples was pure twinned martensite. Experimental results are shown in Figure 10. There are two "plastic" stages during the tension process of $1 \mathrm{~mm}$ diameter SMA wire, the first stage came from the detwinning process of the twinned martensite, and so forth from twinned martensite to single martensite, which can be named "pseudoplasticity" that could be recovered by heating, and the second one was induced by plastic deformation, which was the "real plasticity".

The second uniaxial tension test was carried out with different SMA temperatures. Similarly, SMA wire samples were also pretreated to obtain different initial state. For example, if the sample was heated by boiled water, then cooled by ice water, and then heated to the test temperature of $44.5^{\circ} \mathrm{C}$ by electric current, the initial state will be twinned martensite. While if the sample was heated by boiled water, and then cooled to the test temperature of $44.5^{\circ} \mathrm{C}$, the initial state will be austenite. During the experimental process, testing temperatures were kept constant by adjusting the current intensity.

Elastic moduli of austenite, twinned martensite and detwinned martensite can be determined as $85.5 \mathrm{GPa}$, 28.24 $\mathrm{GPa}$ and $25.75 \mathrm{GPa}$, respectively based on the experimental result, as shown in Figure 11, where " $M$ " means the initial state of the sample as twinned martensite, and " $A$ " as austenite. At different ambient temperatures, the initial elastic moduli of austenite are the same.
In the ambient temperature of $44.5^{\circ} \mathrm{C}$, no matter what initial state is, the critical stress that leads to the stressinduced martensite transformation or the detwinning process of twinned martensite was almost equal. And during the heating recovery process under stress-free conditions, as shown in Figure 12, the critical temperatures of the thermoinduced reverse martensite transformation were almost the same. Otherwise, the unrecoverable stain of the specimen stretched from martensite initial state was a little bit bigger than that from austenite.

For the sample starting from complete austenite, the critical stress inducing martensite transformation increased with the temperature. The statistic result is shown in Figure 13.

2.2.2. SME Test. SMA samples with $5 \mathrm{~mm}$ in diameter were firstly stretched to $4.2 \%, 5.3 \%, 6.6 \%$, and $7.6 \%$, respectively, and then heated in strain-free conditions, this loading cycle was repeated for three times.

For the sample with the loading strain of 5.3\%, variation of stress with strain during the uniaxial tension process is shown in Figure 14, and the variation of strain with temperature during the free heating process is shown in Figure 15. Characters of samples with other loading strains are similar to this.

Experimental results indicated that the plastic deformation increased with the loading times, and during the free recovery process, critical temperature inducing the reverse martensite transformation decreased with loading times, and the recoverable strain became smaller and smaller.

Comparing the samples with different maximum tension strain, variations of stress with strain and those of strain with temperature during the second loading times and free recovery process are shown in Figures 16 and 17, respectively. Test results during the first and the third loading cycles are similar to each other.

According to the experimental curve, the plastic deformation increased with the initial tension strain during the loading and unloading process. And the critical temperature inducing the reverse martensite transformation increased with the initial deformation, and also increased with the plastic deformation.

Additionally, statistical results indicated that the critical temperature inducing the reverse martensite transformation increased with the maximum deformation, decreased with the loading/unloading times, as shown in Figure 18. And the plastic deformation increased with the maximum deformation and the loading/unloading times, as shown in Figure 19.

\subsubsection{Recovery Test under Constrained Condition. The recov-} ery test under constrained condition contained five loading paths: (1) strain-control loading to $4.2 \%$ under normal temperature; (2) heating to $90^{\circ} \mathrm{C}$ and then cooling to $30^{\circ} \mathrm{C}$ under elastic constrained condition in the first time; (3) heating to $90^{\circ} \mathrm{C}$ and then cooling to $30^{\circ} \mathrm{C}$ under elastic constrained condition in the second, third and fourth times; (4) unloading to free condition; (5) heating to $100^{\circ} \mathrm{C}$ and then cooling to $30^{\circ} \mathrm{C}$ under free condition. 


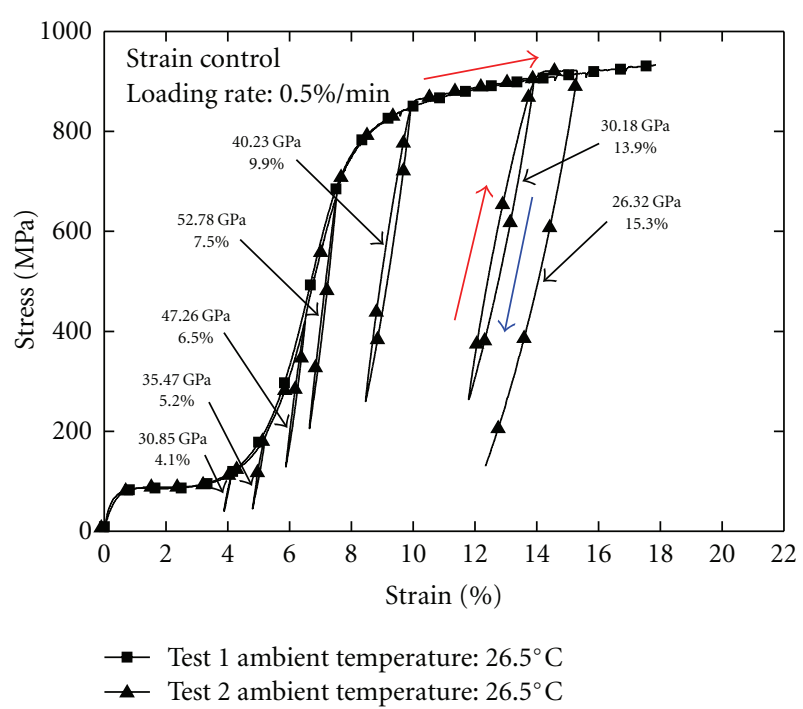

(a) SMA diameter: $1 \mathrm{~mm}$

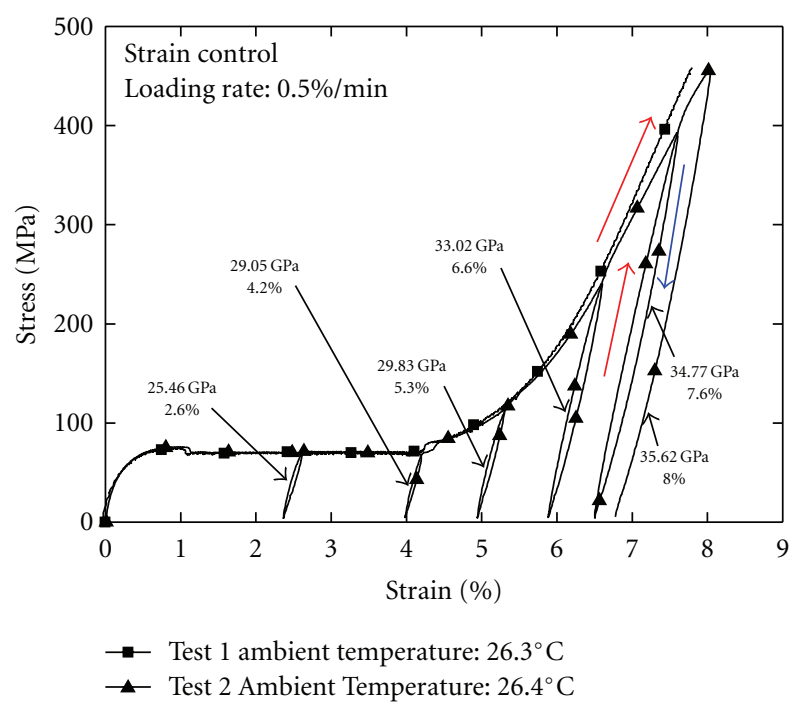

(b) SMA diameter: $5 \mathrm{~mm}$

FIgURe 10: Uniaxial tension test.

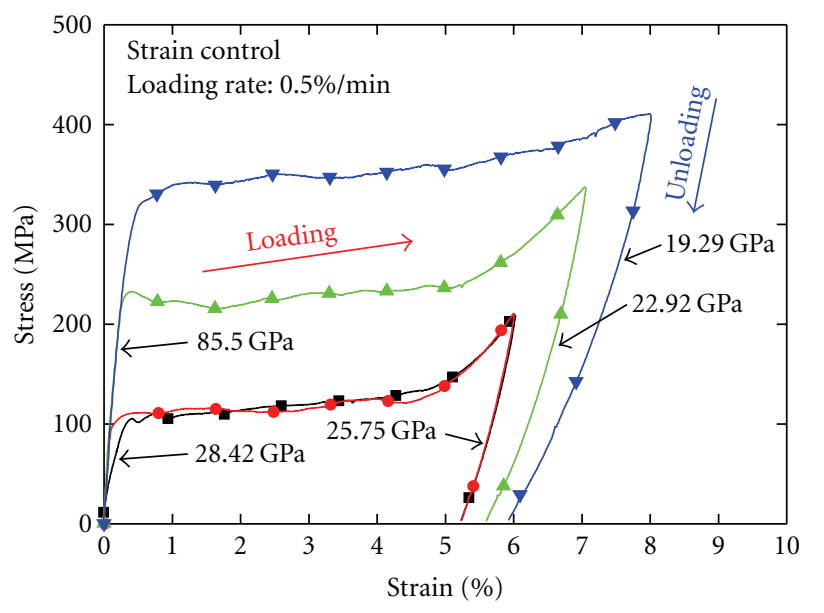

$\rightarrow-M$ SMA temperature $=44.5^{\circ} \mathrm{C} \longrightarrow A$ SMA temperature $=54.5^{\circ} \mathrm{C}$

$\rightarrow A$ SMA temperature $=44.5^{\circ} \mathrm{C} \rightarrow-A$ SMA temperature $=65.5^{\circ} \mathrm{C}$

FIgURE 11: Uniaxial tension processes under different ambient temperatures.

In the initial state of twinned martensite, the elastic constrained recovery test of SMA is shown in Figure 20. Test results under different constrained conditions, initial state and maximum strain are similar in form.

Because constraint elastic modulus during the first heating process was smaller than that of the subsequent second to fifth heating/cooling process, relationships between stress and strain, stress and temperature, and temperature and strain, were different correspondingly. In the first heating process, the stress increased gradually, the strain decreased and some deformation of SMA restored. In the following heating and cooling process, the strain almost remained, the stress increased with temperature rising and decreased

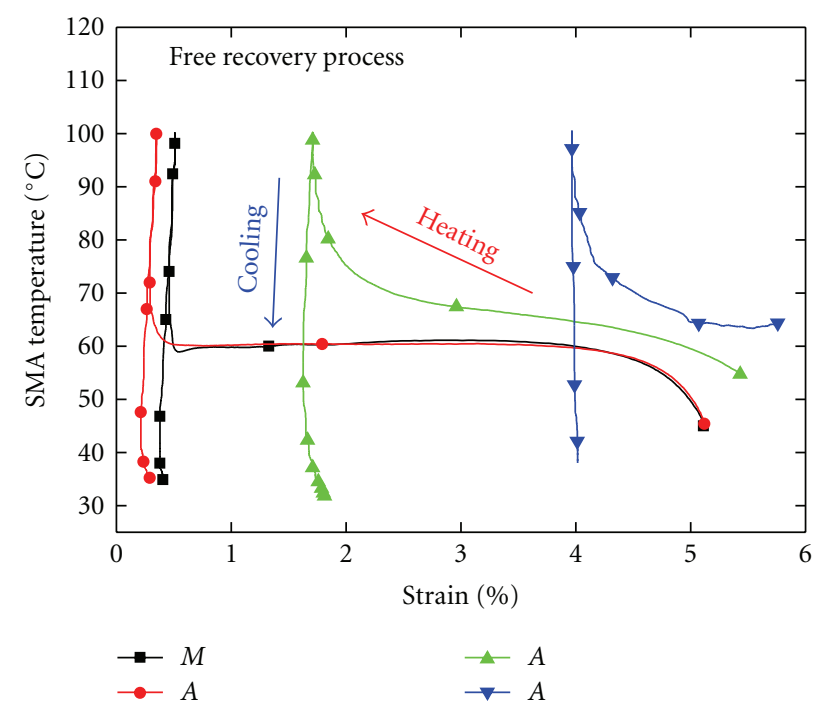

Figure 12: Free recovery processes of SMA after loading with different temperatures.

with temperature dropping, forming a hysteretic circle, and the variation rate of stress with temperature changed in the range of $2.4 \mathrm{MPa} \sim 8 \mathrm{MPa} /{ }^{\circ} \mathrm{C}$. During the heating process under stress free state, the strain recovery course of SMA with temperature showed two obvious stages, as shown in Figure 20(c).

\section{Constitutive Model}

3.1. Physical Equation. According to the macro-phenomenon, deformation of SMA during thermo and stress loading process can be divided into four components: (1) macro 


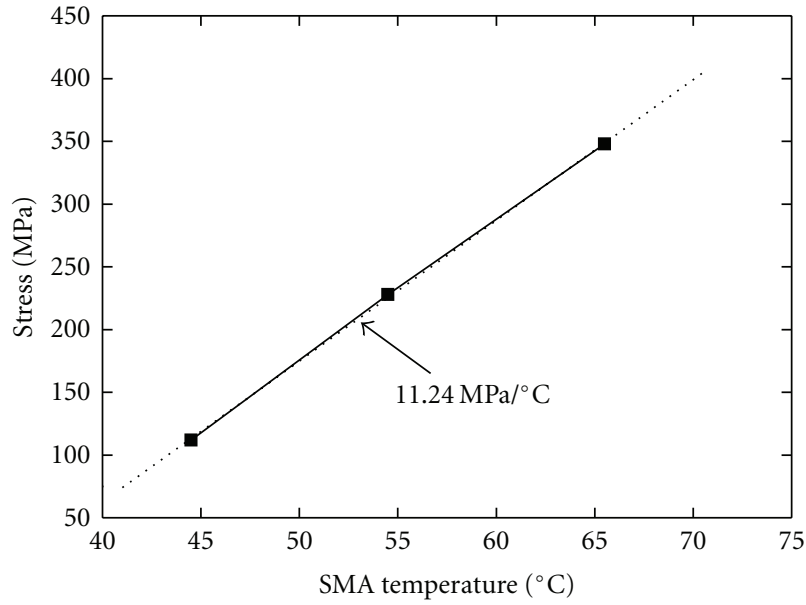

FIGURE 13: Variation of critical strain with temperature of stress induced martensite transformation.

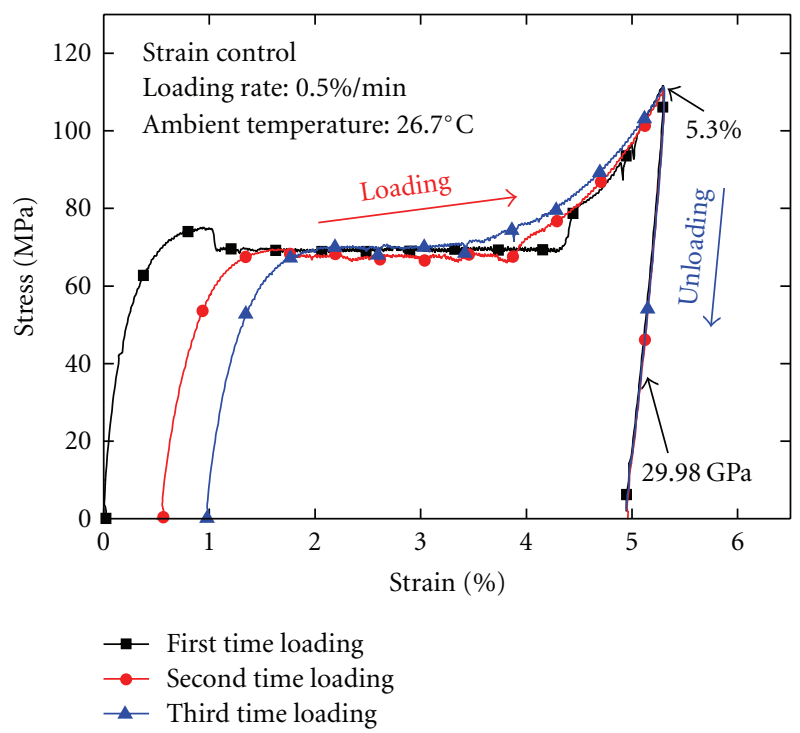

Figure 14: Stress-strain curve of SMA in different loading times.

recoverable deformation caused by martensite transformation, mainly determined by single crystal martensite percentage; (2) elastic deformation; (3) thermal expansion deformation; (4) plastic deformation. Thus, the macro physical equation of SMA in strain form during the temperature and stress loading process can be expressed as

$$
\begin{aligned}
\varepsilon= & \varepsilon^{R}+\varepsilon^{E}+\varepsilon^{T}+\varepsilon^{P} \\
= & \varepsilon_{\mathrm{res}} \bullet \xi_{\mathrm{SM}}+\frac{\sigma}{\left(\xi_{\mathrm{SM}} \bullet E_{\mathrm{SM}}+\xi_{\mathrm{TM}} \cdot E_{\mathrm{TM}}+\xi_{\mathrm{A}} \cdot E_{\mathrm{A}}\right)} \\
& +\left(\xi_{\mathrm{SM}} \bullet \eta_{\mathrm{SM}}+\xi_{\mathrm{TM}} \bullet \eta_{\mathrm{TM}}+\xi_{A} \bullet \eta_{A}\right) \bullet\left(T-T_{0}\right)+\varepsilon^{P},
\end{aligned}
$$

where $\varepsilon$ is the dimensionless macro total strain, positive for stretch; $\varepsilon^{R}, \varepsilon^{E}, \varepsilon^{T}, \varepsilon^{P}$ denote the dimensionless recoverable transformation, elastic, thermal expansion and plastic

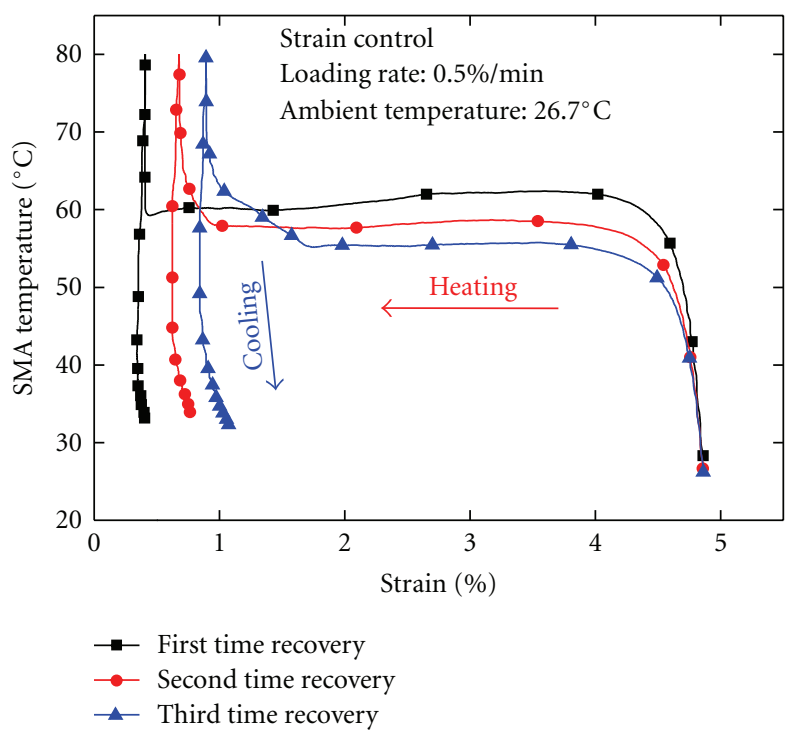

FIGURE 15: Temperature-strain curve of SMA in different loading times.

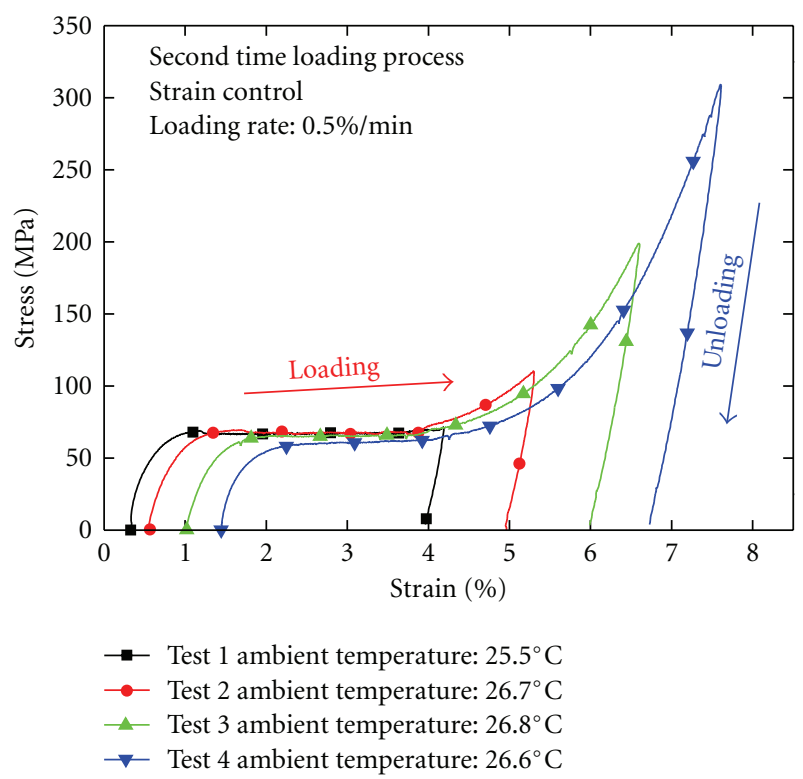

FIGURE 16: Stress-strain curve of SMA in different maximum loading deformations.

strains, respectively; $\varepsilon_{\text {res }}$ is the maximum recoverable strain; $\sigma$ is the macro stress, positive for stretch (unit: $\mathrm{MPa}$ ). $E_{\mathrm{SM}}, E_{\mathrm{TM}}$, $E_{A}$ denote the elastic moduli of single crystal martensite, twinned martensite and austenite, respectively (units: GPa). $\eta_{\mathrm{SM}}, \eta_{\mathrm{TM}}, \eta_{\mathrm{A}}$ denote the thermal expansion coefficients of single crystal martensite, twinned martensite and austenite, respectively (units: $\left(1 /{ }^{\circ} \mathrm{C}\right) . \xi_{\mathrm{SM}}, \xi_{\mathrm{TM}}, \xi_{\mathrm{A}}$ denote the quality percentages of single crystal martensite, twinned martensite and the austenite, respectively, with $\xi_{\mathrm{SM}}+\xi_{\mathrm{TM}}+\xi_{\mathrm{A}}$ equals to 1. $T$ is the temperature of SMA (unit: ${ }^{\circ} \mathrm{C}$ ). $T_{0}$ is the initial temperature of SMA (unit: ${ }^{\circ} \mathrm{C}$ ). 


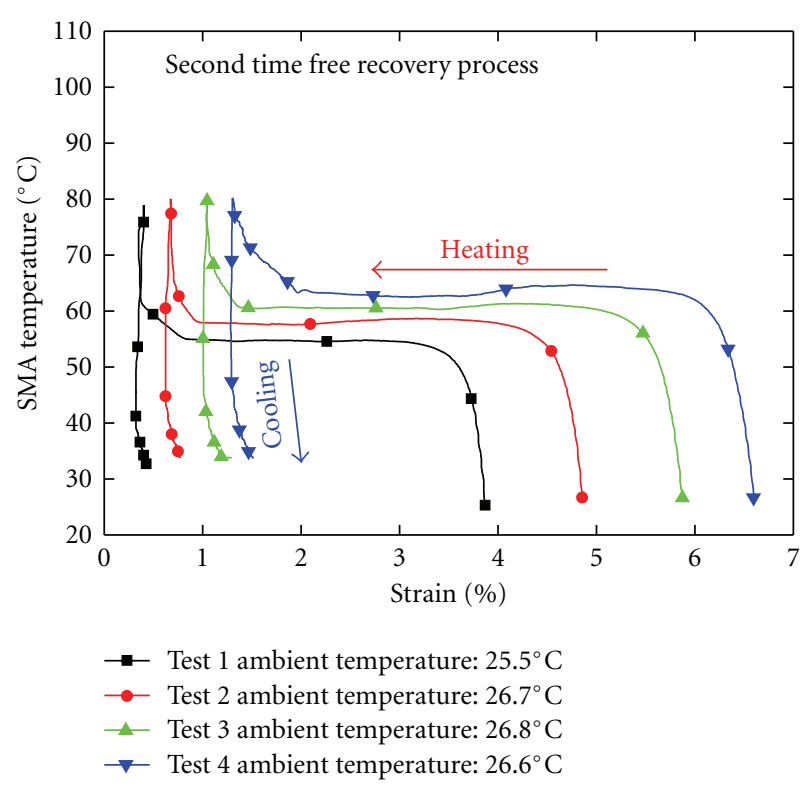

FIGURE 17: Temperature-strain curve of SMA in different maximum loading deformations.

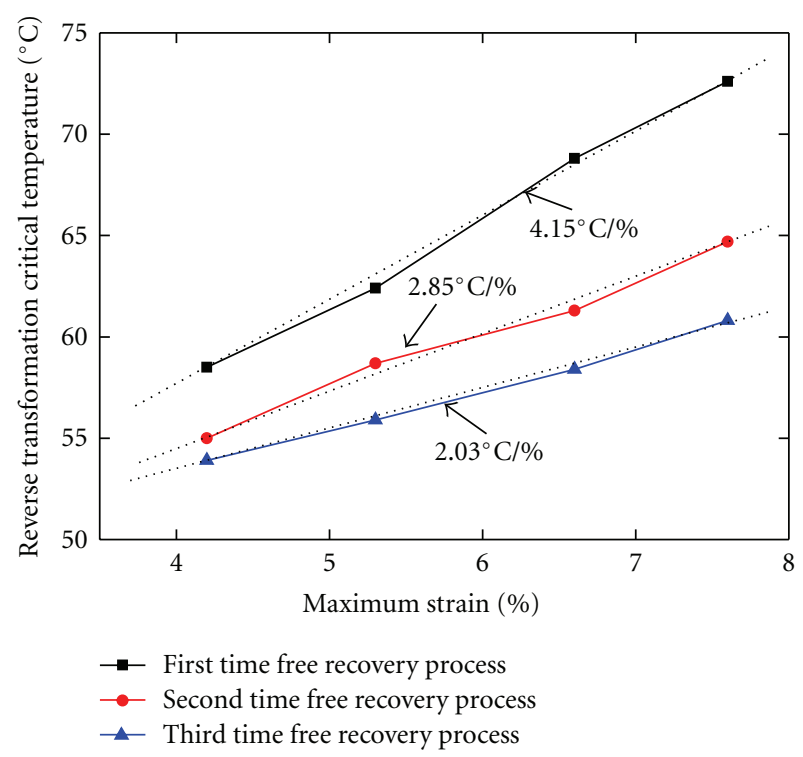

FIGURE 18: Variation property of transformation critical temperature with maximum loading strain.

3.2. Kinetics Equation. DSC experiments showed that there were no obvious transformation start and finish temperatures during the transformation process. In this section, the single transformation characteristic temperatures, as well as the parameters that reflect the width of the endothermic and exothermic peaks, are adopted to simulate the phase transformation of SMA, and the corresponding kinetics equation is established at the same time.

During the transformation process, there are three crystal structures in SMA material, twinned martensite, single martensite, and austenite, respectively thus there are six

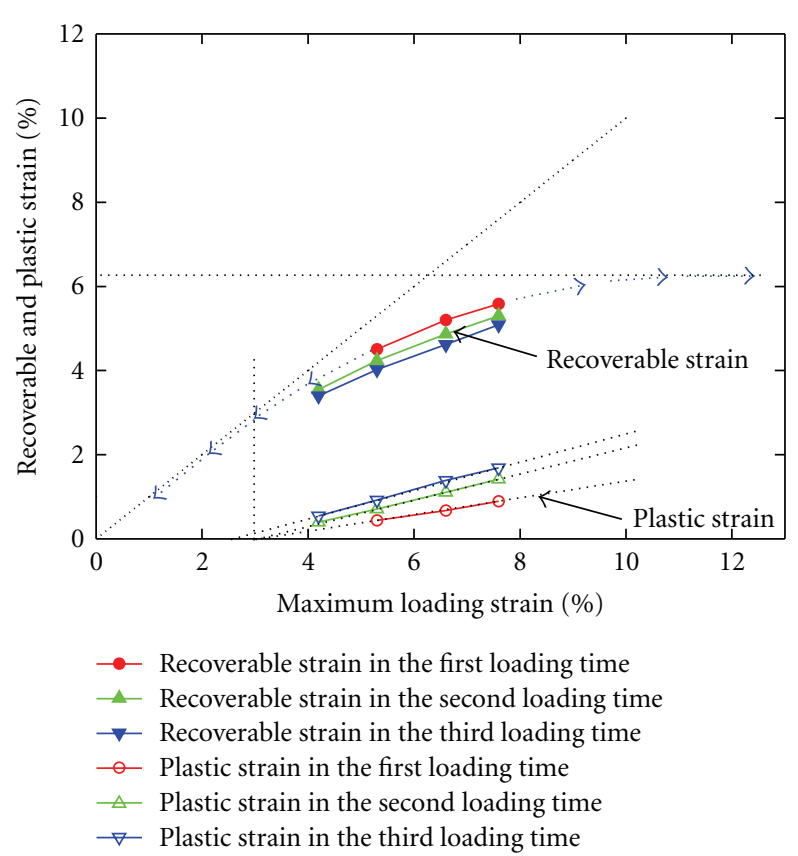

FIGURE 19: Variation property of recoverable and plastic strain with maximum loading strain.

phase transformation processes theoretically. In this section, each phase transition process is analyzed based on the DSC experiments, and the corresponding transformation principles and conditions are presented.

\subsubsection{Transformation from Twinned Martensite to Austenite.} Transformation condition: assuming in one-dimensional terms, only heating can lead to this phase transition from twinned martensite to austenite.

Transformation principle: for the transformation from twinned martensite to austenite, if the reverse transformation from austenite to twinned martensite did not occur during the process, a small cooling will not affect its subsequent transformation process, as shown in Figure 7.

However, if the reverse transformation process happened and induced a lot of austenitic to twinned martensite, then the extent of the following transformation from twinned martensite to austenite required reduction in accordance with the quality fraction of the current twinned martensite, as shown in Figure 4.

Thus, the kinetics equation from twinned martensite to austenite can be acquired as

$$
\xi_{\mathrm{TM}}=\frac{\xi_{\mathrm{TM} 0}}{1+e^{\left(\left(T-T_{A}\right) / A\right)}},
$$

here $\xi_{\mathrm{TM} 0}$ is the initial quality fraction of twinned martensite; $T_{A}$ is the characteristic temperature for austenite transformation, and numerically equivalent to the temperature where the complete austenite transformation goes into the half, and is equivalent to the peak temperature of the DSC endothermic curve approximately; $A$ is the transformation parameter reflecting the width of the endothermic peak, and 


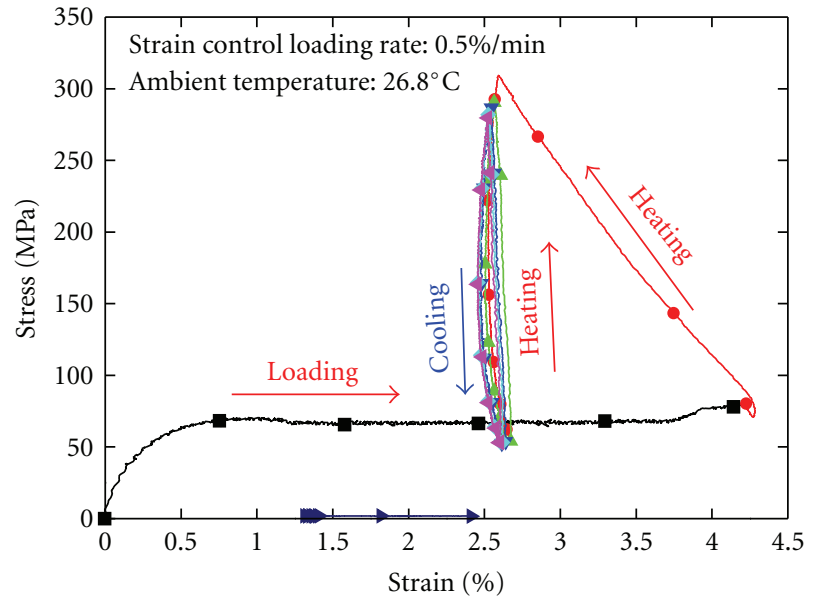

(a) Stress-strain curve

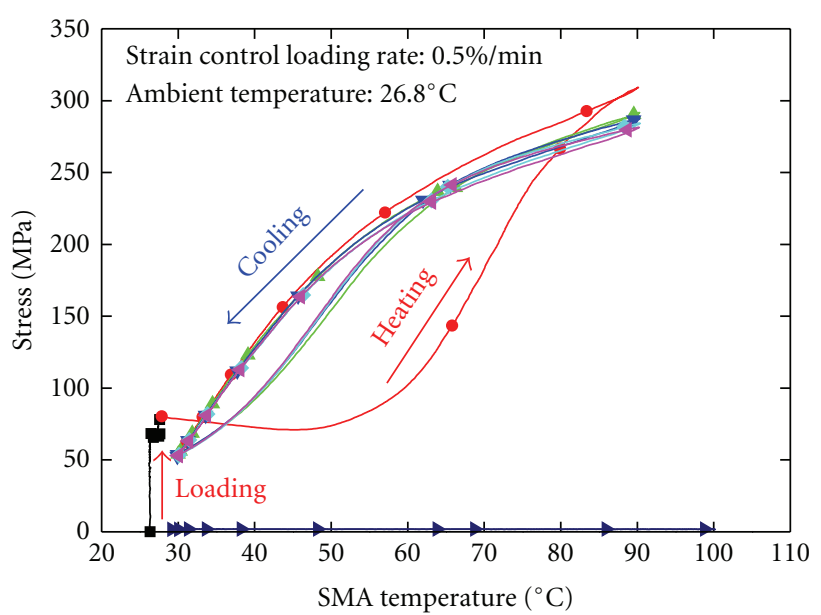

(b) Stress-temperature curve

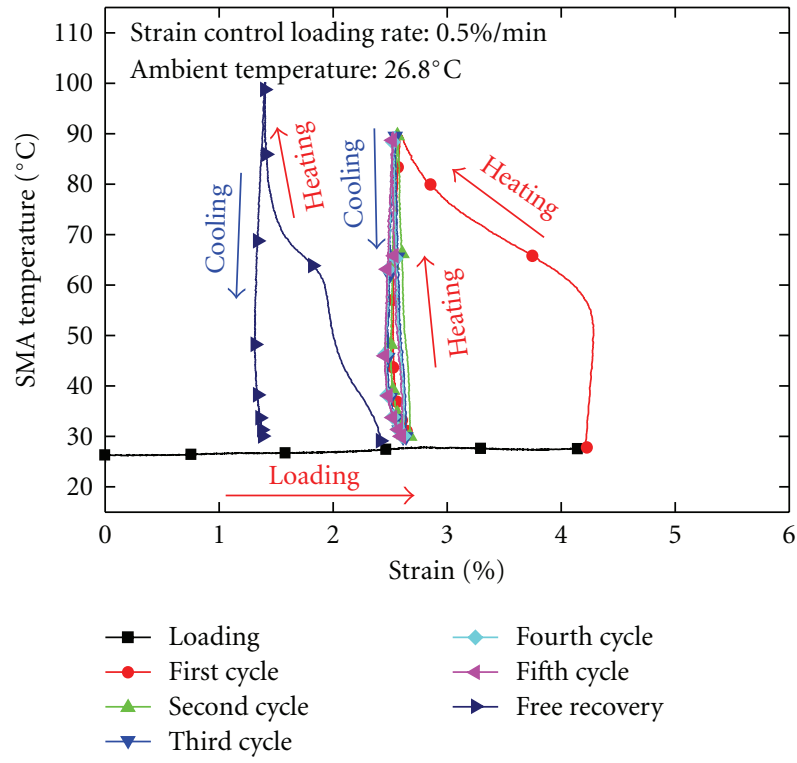

(c) Temperature-strain curve.

FIgURE 20: Constrained recovery test.

numerically equivalent to $\left(\left(A_{f}-A_{s}\right) / 2 e\right)$, here $A_{s}, A_{f}$ denote the start and finish temperatures of austenite transformation defined by the traditional method. $e$ is the natural constant and equals to 2.71828 .

\subsubsection{Transformation from Austenite to Twinned Martensite.} Transformation condition: assuming in one-dimensional terms, only cooling can lead to this phase transition from austenite to twinned martensite.

Transformation principle: for the transformation from austenite to twinned martensite, if the reverse transformation from twinned martensite to austenite did not occur during the process, a small heating will not affect its subsequent transformation process, as shown in Figure 6.

However, if the reverse transformation process happened and induced a lot of twinned martensite to austenitic, the extent of the following transformation from austenite to twinned martensite would require reduction in accordance with the quality fraction of the current austenite, as shown in Figure 5.

Thus, the kinetics equation from austenite to twinned martensite can be acquired as

$$
\xi_{\mathrm{TM}}=\frac{\left(1-\xi_{\mathrm{TM} 0}\right)}{1+e^{\left(\left(T-T_{\mathrm{M}}\right) / M\right)}}+\xi_{\mathrm{TM} 0},
$$

where $T_{M}$ is the characteristic temperature for martensite transformation, and numerically equals to the temperature where the complete martensite transformation goes into the half, and is equivalent to the peak temperature of the DSC exothermic curve approximately; $M$ is the transformation parameter reflecting the width of the exothermic peak, and numerically equivalent to $\left(M_{s}-M_{f}\right) / 2 e$, here $M_{s}$, $M_{f}$ denote the start and finish temperatures of martensite transformation defined by the traditional method. 


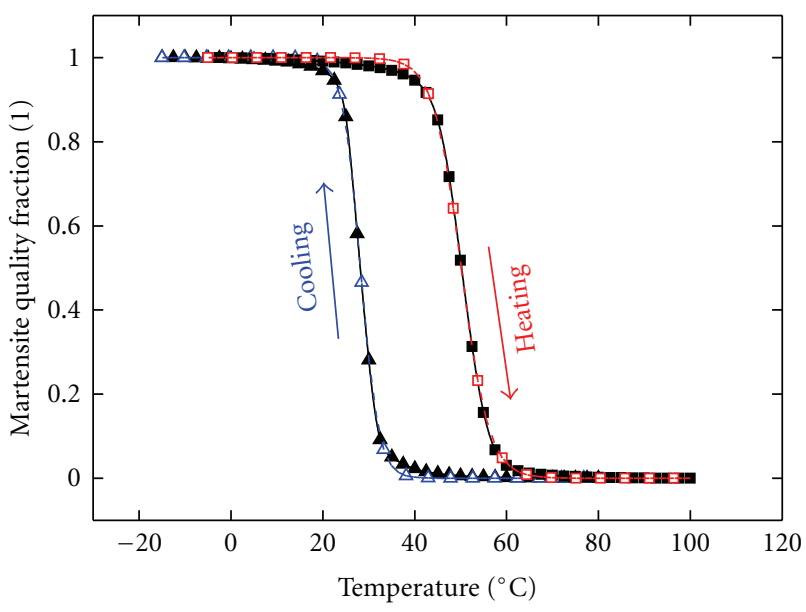

$\begin{array}{ll}\text { Martensite transformation } & \text { Austenite transformation } \\ -\_ \text {Experimental curve } & - \text { Experimental curve } \\ -\Delta-\text { Numerical curve } & -\square-\text { Numerical curve }\end{array}$

Figure 21: Comparison between experimental and calculated curve of martensite quality fraction versus temperature.

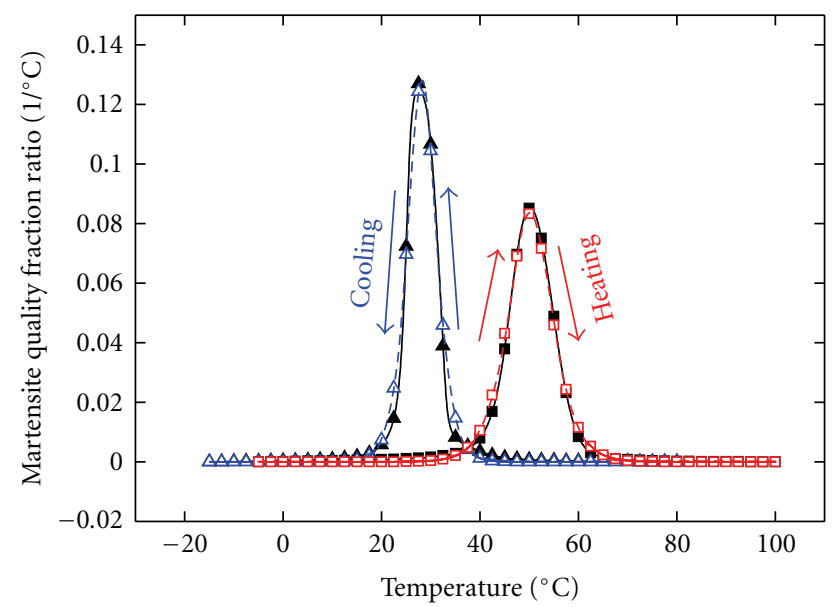

Figure 22: Comparison between experimental and calculated curve of martensite quality fraction ratio versus temperature.

3.2.3. Transformation from Twinned Martensite to Single Martensite. Transformation condition: assuming in one-dimensional terms, only the increase of stress can lead to this phase transition from twinned martensite to single martensite.

Transformation principle: during the uniaxial tension process, for the transformation from twinned martensite to single martensite, if the none macro press stress occur during unloading process, this unloading will not affect the transformation of the subsequent reloading process.

During the phase transition process, taking the twinned martensite as austenitic, this transformation will be similar to the transformation from austenite to single martensite,

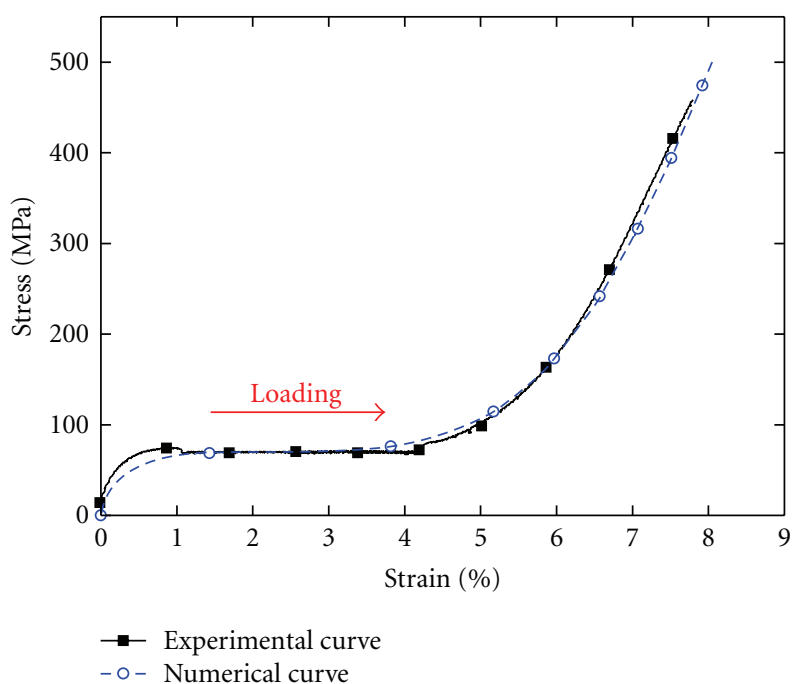

FIGURE 23: Comparison between experimental and calculated curve of uniaxial tension process.

only with the different phase transition peak temperature, and the transformation parameters and impact coefficient of the stress on the temperature still adopted the values of transformation from austenite to twinned martensite.

Therefore, based on the kinetics of the transformation from austenite to twinned martensite, kinetics of the transformation from twinned martensite to single one can be achieved as

$$
\xi_{\mathrm{SM}}=\frac{1}{1+e^{\left(\left(T-\left(\sigma^{i} / C_{M^{\prime}}\right)-T_{M^{\prime}}\right) / M^{\prime}\right)}}
$$

or

$$
\xi_{\mathrm{TM}}=\frac{1}{1+e^{\left(\left(\sigma^{i}-\sigma_{\text {crit }}^{i}\right) /\left(C_{M^{\prime}} \bullet M^{\prime}\right)\right)}}
$$

where $\sigma^{i}$ denotes the average internal stress between the crystals (unit: $\mathrm{MPa}$ ); $T_{M^{\prime}}$ is the transformation characteristic temperature; $M^{\prime}$ is the transformation parameter; $C_{M^{\prime}}$ denotes the impact coefficient of stress on transformation temperature; $\sigma_{\text {crit }}^{i}$ denotes the average internal stress between the crystals where the full detwinned process occurred on the half (unit: $\mathrm{MPa}$ ).

3.2.4. Transformation from Single Martensite to Twinned One. Transformation condition: for uniaxial tension process, macrostress and the temperature will not induce the transformation from single martensite to twinned one. However, under repeated stretch-press loading, the martensites with different directions will change its direction repeatedly, and this process corresponds to the SMA rubber-like plastic phenomenon.

3.2.5. Transformation from Single Martensite to Austenite. Transformation condition: assuming in one-dimensional terms, heating and the decrease of stress can lead to this phase transition from single martensite to austenite. 


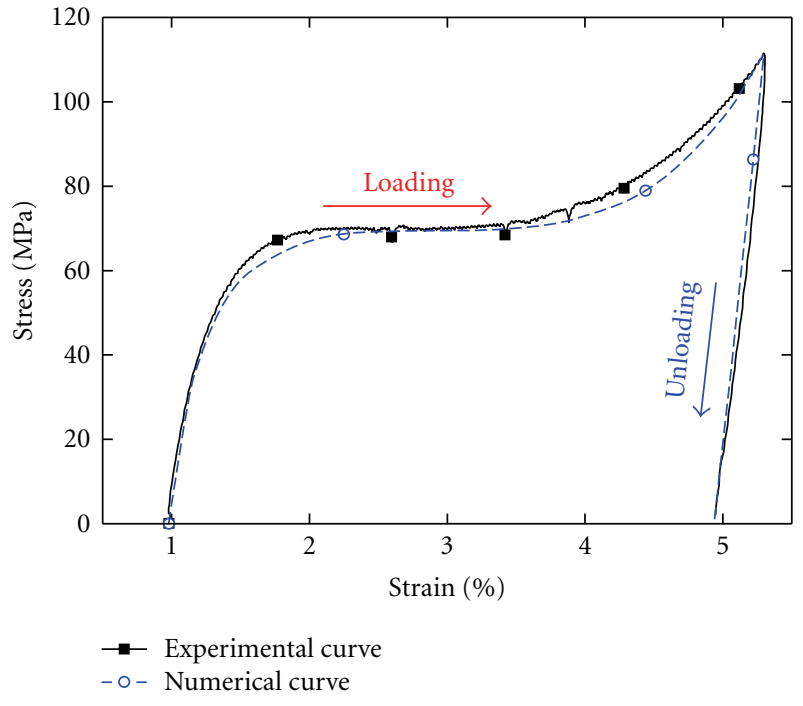

(a) Stress-strain curve

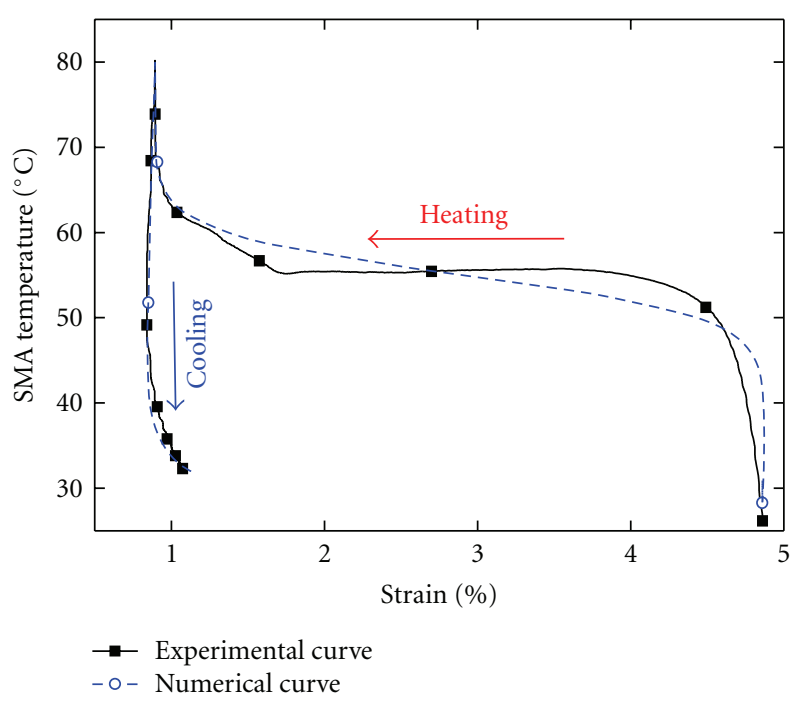

(b) Temperature-strain curve

FIgURE 24: Comparison between experimental and calculated curve of the third times SME process.

TABLE 1: Transformation parameters determined by DSC test.

\begin{tabular}{lcc}
\hline & Transformation characteristics temperature $\left({ }^{\circ} \mathrm{C}\right)$ & Transformation parameter $\left({ }^{\circ} \mathrm{C}\right)$ \\
\hline Martensite transformation process & 28.2 & 1.947 \\
Reverse martensite transformation process & 50.14 & 2.999 \\
\hline
\end{tabular}

Transformation principle: as similar to the transformation from twinned martensite to austenite, for the transformation from single martensite to austenite, if the reverse transformation from austenite to single martensite did not occur during the process, a small cooling or increase of stress will not affect its subsequent transformation process.

However, if the reverse transformation process happened and induced a lot of austenitic to single martensite, then the extent of the following transformation from single martensite to austenite would require reduction in accordance with the quality percentage of the current single martensite.

Thus, the kinetics equation from single martensite to austenite can be acquired as

$$
\xi_{\mathrm{SM}}=\frac{\xi_{\mathrm{SM} 0}}{1+e^{\left(T-\left(\sigma^{i} / C_{A}\right)-T_{A}\right) / A}},
$$

where $\xi_{\mathrm{SM} 0}$ is the initial quality fraction of single martensite.

\subsubsection{Transformation from Austenite to Single Martensite.} Transformation condition: Assuming in one-dimensional terms, cooling and increase of stress can lead to this phase transition from austenite to single martensite.

Transformation principle: As similar to the transformation from austenite to twinned martensite, for the transformation from austenite to single martensite, if the reverse transformation from single martensite to austenite did not occur during the process, a small heating or decrease of stress will not affect its subsequent transformation process.
However, if the reverse transformation process happened and induced a lot of single martensite to austenitic, then the extent of the following transformation from austenite to single martensite required reduction in accordance with the quality percentage of the current austenite.

Thus, the kinetics equation from austenite to single martensite can be acquired as

$$
\xi_{\mathrm{SM}}=\frac{\left(1-\xi_{\mathrm{SM} 0}\right)}{1+e^{\left(T-\left(\sigma^{i} / C_{M}\right)-T_{M}\right) / M}}+\xi_{\mathrm{SM} 0} .
$$

3.2.7. Parameter Variation Properties of the Kinetics. At the same time, DSC experiments showed that, even for the same material components and the same diameter of the SMA, the transformation of the material would be very different after experiencing loading and plastic deformation, as shown in Figure 8, and these changes must be considered in the constitutive model.

For the SMA of $1 \mathrm{~mm}$ in diameter, in austenite transformation process, after undergoing the plastic deformation, the transformation peak temperature changes from $50.25^{\circ} \mathrm{C}$ to $121.0^{\circ} \mathrm{C}$, and the transformation parameter changes from 3.25 to 10.25 . Similarly, in the martensite transformation process, the transformation peak temperature changes from $27.55^{\circ} \mathrm{C}$ to $45.9^{\circ} \mathrm{C}$, and the transformation parameter changes from 1.93 to 11.28 .

It must be pointed out that these variations are apt for the SMA with $1 \mathrm{~mm}$ in diameter. For the SMA with $5 \mathrm{~mm}$ in diameter, the change scope of these parameters will be different and can be determined by experiment. 


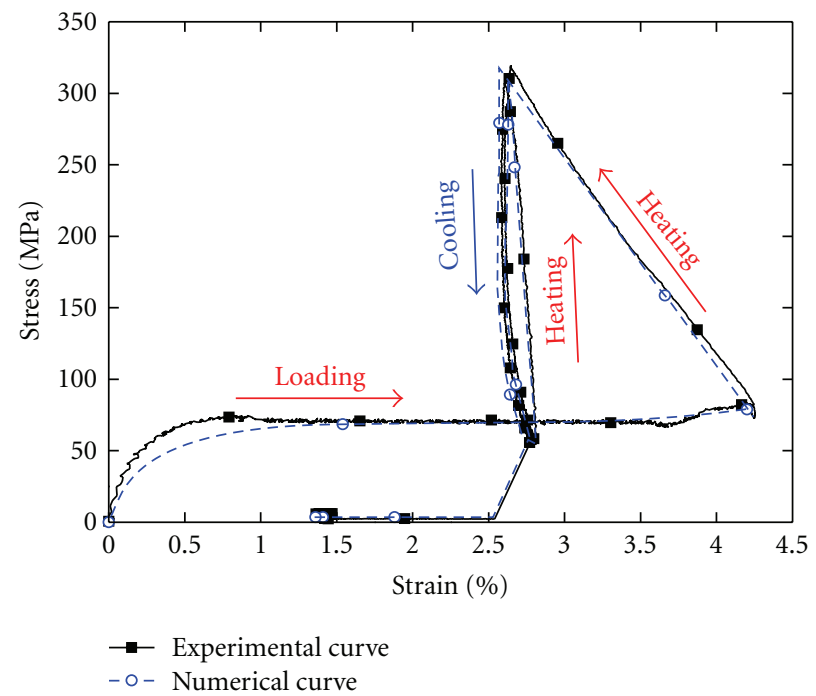

(a) Stress-strain curve

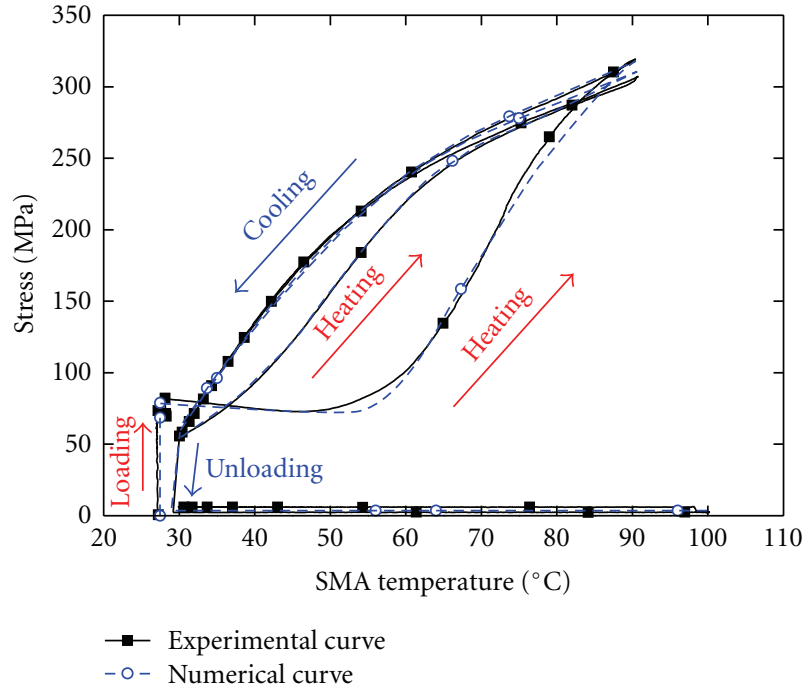

(b) Stress-temperature curve

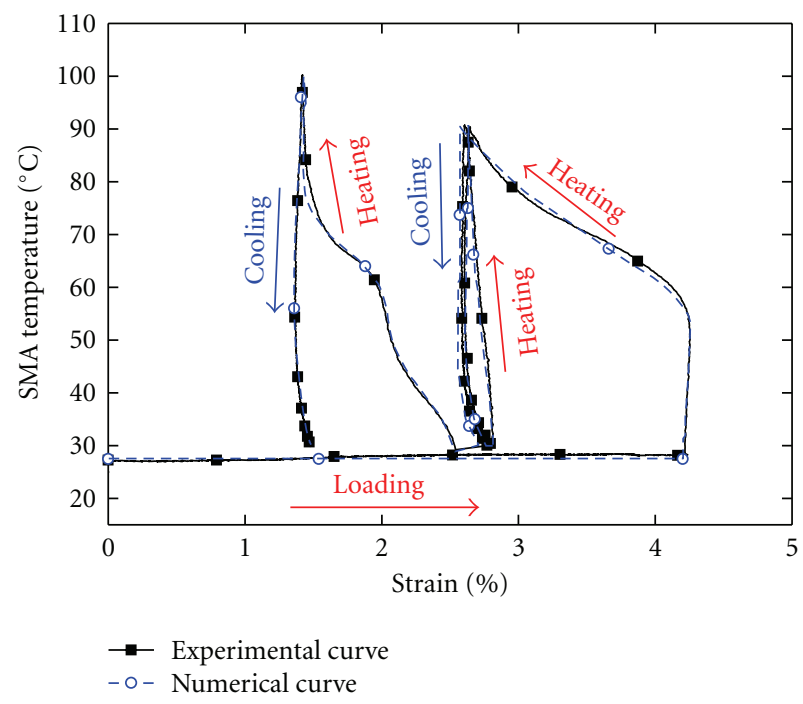

(c) Temperature-strain curve

FIGURE 25: Comparison between experimental and calculated curve of constrained recovery process.

3.2.8. Consideration of the Plastic Deformation. In the first loading process, after stretching to different deformations and heating under free condition, plastic deformations for different initial deformations are shown in Figure 19.

Experimental results indicated that, when the maximum tensile strain exceeded $3 \%$, the plastic deformation increment would be linearly related to the maximum tensile strain increment; thus, the experience equation of the plastic evolution could be achieved as follows

$$
\varepsilon^{P}=0.198 \times(\varepsilon-0.03), \quad \varepsilon^{P} \geq 0 .
$$

It must be pointed out that this equation is the fitted results of the uniaxial tensile test at room temperature. For another SMA material under different temperature, variation of the plastic deformation with the strain will be very different, additionally, this equation is only applicable to simulate plastic evolution characteristics during the first loading process, but not the second and the third loading processes.

\section{Numerical Simulation and Comparison with the Experimental Results}

Two parts are included in this section, one is the determination of the parameters in the kinetics equation based on the DSC test results and the calculation of the phase transformation, uniaxial tension, SME and the constrained recovery curves, and the other is the comparison with the experimental results.

4.1. Determination of the Parameters in Constitutive Equation. The transformation characteristics were calculated through 
the kinetics equation directly and compared with the experimental results. The SMA uniaxial tension, SME and the constrained recovery stress-strain-temperature curves were calculated through the incremental form of the constitutive model. The parameters used in the calculating process were determined through the following principles.

(1) Transformation characteristic temperature and parameters of the kinetics were determined through the DSC test results.

(2) The macro physical parameters, such as the elastic modulus, thermal expansion coefficient adopted the experimental result.

(3) Because the characteristics temperature and transformation parameters change with the loading process, therefore, in the calculating program, these parameters were adjusted according to the test results of SMA with $1 \mathrm{~mm}$ in diameter.

(4) The critical value of the internal stress was adjusted based on the experimental critical stress in uniaxial tension.

4.2. Verification of SMA Transformation Property. According to the variation curve of martensite quality percentage with the temperature of martensite transformation and reverse one (Figure 3), the parameters of the kinetics equation can be achieved through the numerical fitting of the test results, as shown in Table 1.

Using the parameters calibrated by the numerical fitting, variation curve of martensite quality percentage with temperature can be calculated. The results with comparison of the test ones are shown in Figure 21. Additionally, variation curve of martensite quality percentage changing rate with temperature can be calculated as shown in Figure 22, with comparison of the test ones.

These comparisons between the numerical and the experimental results indicate that the kinetics equation proposed in this paper can simulate the transformation properties of SMA more practically, there are not obvious start and finish temperatures in the calculated curve during the transformation process, the calculated exothermic and endothermic peaks are well consistent with the experimental ones.

4.3. Comparison of the Uniaxial Tension, SME, and Controlled Recovery Curve. Through the constitutive model with differential form, the uniaxial tension, SME and controlled recovery curve of SMA with $5 \mathrm{~mm}$ in diameter can be calculated by program, and compared with the test results, as shown in Figures 23, 24, and 25.

Numerical results indicate that, based on the well forecast for the phase transformation properties, the constitutive model can simulate the uniaxial tension, SME and controlled recovery process of SMA more accurately.

\section{Conclusion}

A constitutive model in strain form with a new simple empirical kinetics equation is presented based on the DSC and uniaxial tension test in this paper, and the plastic deformation is considered. Transformation temperature parameters that denote the peak temperature and peak width of the endothermic and exothermic process were adopted to simulate the transformation characteristics of SMA more practically. Transformation conditions and properties of the six transformation processes were analyzed.

At the same time, physical and kinetics parameters were identified through the DSC and the uniaxial test analysis for SMA, programs were adopted for calculating the phase transformation and uniaxial tension process. Comparison between the simulating and experimental results shows that the established constitutive model in this paper can simulate the martensite and the reverse transformation, as well as the uniaxial tension, SME, and constraint recovery process, more accurately.

\section{Acknowledgment}

This work was supported by the Department of Transportation of Henan Province, China (Grant no. 2004P449); and The National Natural Science Foundation for Distinguished Young Scholars, China (Grant no. 50225927).

\section{References}

[1] A. B. Greninger and V. G. Mooradian, "Strain transformation in metastable beta copper-zinc and beta copper-tin alloys," Transactions of the Metallurgical Society of AIME, vol. 128, pp. 337-368, 1938.

[2] W. J. Buehler, J. V. Gilfrich, and R. C. Wiley, "Effect of lowtemperature phase changes on the mechanical properties of alloys near composition TiNi," Journal of Applied Physics, vol. 34, no. 5, pp. 1475-1477, 1963.

[3] L. Delaey, R. V. Krishnan, H. Tas, and H. Warlimont, "Thermoelasticity, pseudoelasticity and the memory effects associated with martensitic transformations-part 1: structural and microstructural changes associated with the transformations," Journal of Materials Science, vol. 9, no. 9, pp. 1521-1535, 1974.

[4] R. V. Krishnan, L. Delaey, H. Tas, and H. Warlimont, "Thermoplasticity, pseudoelasticity and the memory effects associated with martensitic transformations-part 2: the macroscopic mechanical behaviour," Journal of Materials Science, vol. 9, no. 9, pp. 1536-1544, 1974.

[5] H. Warlimont, L. Delaey, R. V. Krishnan, and H. Tas, "Thermoelasticity, pseudoelasticity and the memory effects associated with martensitic transformations-part 3: thermodynamics and kinetics," Journal of Materials Science, vol. 9, no. 9, pp. 1545-1555, 1974.

[6] F. Hiroyasu, Shape Memory Alloys, Gordon and Breach, New York, NY, USA, 1987.

[7] K. Otsuka and C. M. Wayman, Shape Memory Materials, Cambridge University Press, Cambridge, UK, 1998.

[8] K. Tanaka and S. Nagaki, "A thermomechanical description of materials with internal variables in the process of phase transitions," Ingenieur-Archiv, vol. 51, no. 5, pp. 287-299, 1982. 
[9] K. Tanaka, "A thermomechanical sketch of shape memory effect: one-dimensional tensil behavior," Res Mechanica, vol. 18, no. 3, pp. 251-263, 1986.

[10] L. Chen, Constitutive modeling of shape memory alloys, Ph.D. thesis, VPI, Blacksburg, Va, USA, 1990.

[11] L. C. Brinson, "One-dimensional constitutive behavior of shape memory alloys: thermomechanical derivation with nonconstant material functions and redefined martensite internal variable," Journal of Intelligent Material Systems and Structures, vol. 4, no. 2, pp. 229-242, 1993.

[12] J. Zhu, N. Liang, W. Huang, K. M. Liew, and Z. Liu, "A thermodynamic constitutive model for stress induced phase transformation in shape memory alloys," International Journal of Solids and Structures, vol. 39, no. 3, pp. 741-763, 2002.

[13] Q. P. Sun and K. C. Hwang, "Micromechanics modelling for the constitutive behavior of polycrystalline shape memory alloys-I. Derivation of general relations," Journal of the Mechanics and Physics of Solids, vol. 41, no. 1, pp. 1-17, 1993.

[14] Q. P. Sun and K. C. Hwang, "Micromechanics modelling for the constitutive behavior of polycrystalline shape memory alloys-II. Study of the individual phenomena," Journal of the Mechanics and Physics of Solids, vol. 41, no. 1, pp. 19-33, 1993.

[15] M. Brocca, L. C. Brinson, and Z. P. Bažant, "Threedimensional constitutive model for shape memory alloys based on microplane model," Journal of the Mechanics and Physics of Solids, vol. 50, no. 5, pp. 1051-1077, 2002. 

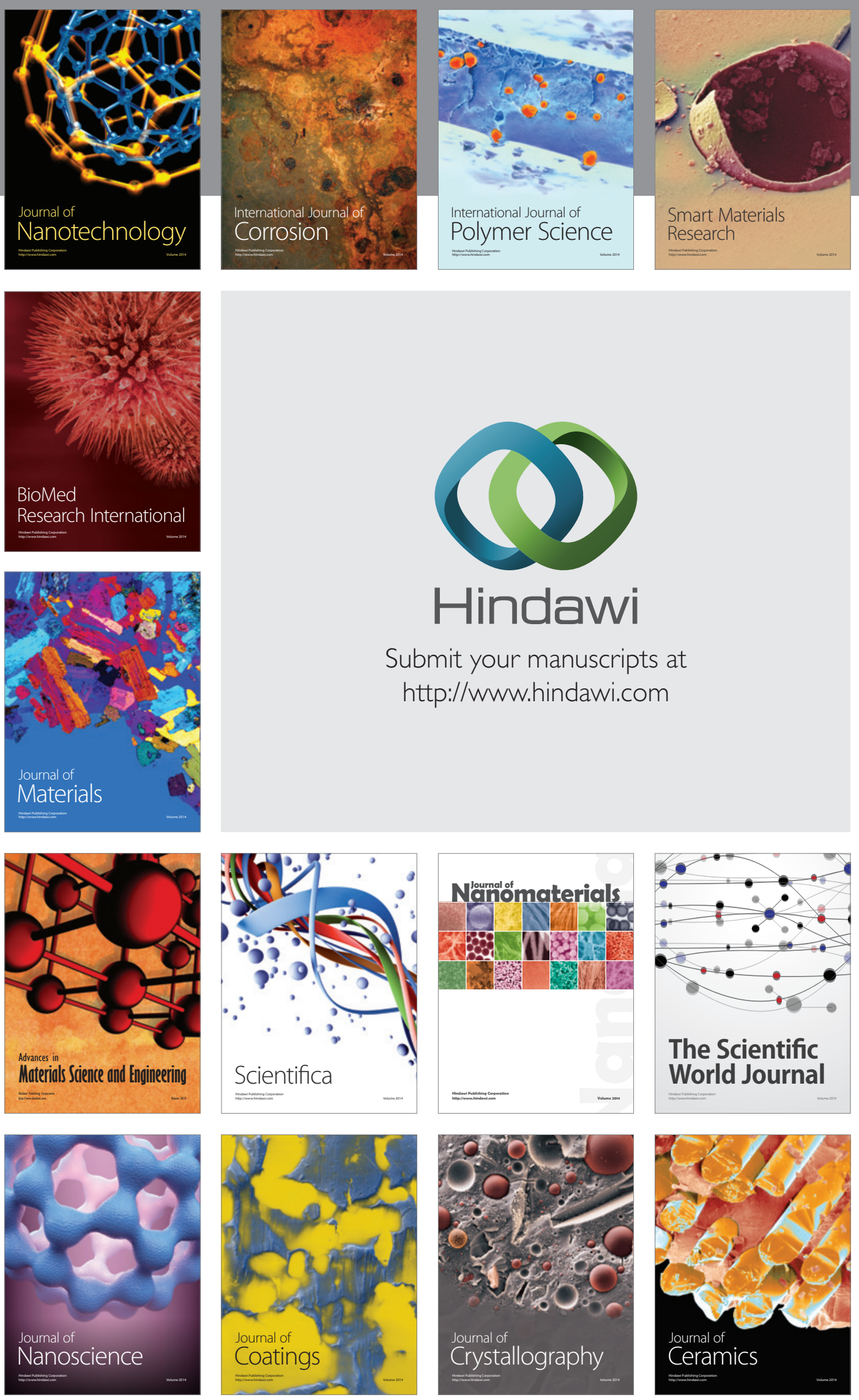

The Scientific World Journal

Submit your manuscripts at

http://www.hindawi.com

\section{World Journal}

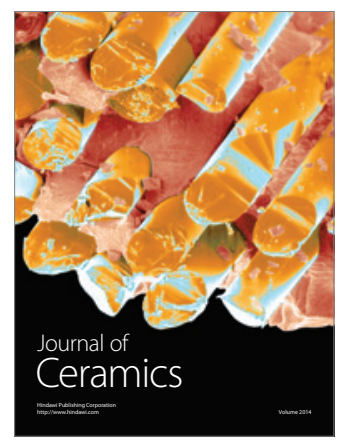

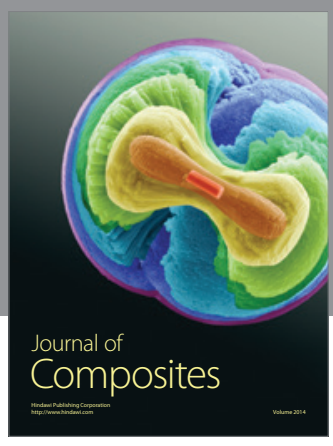
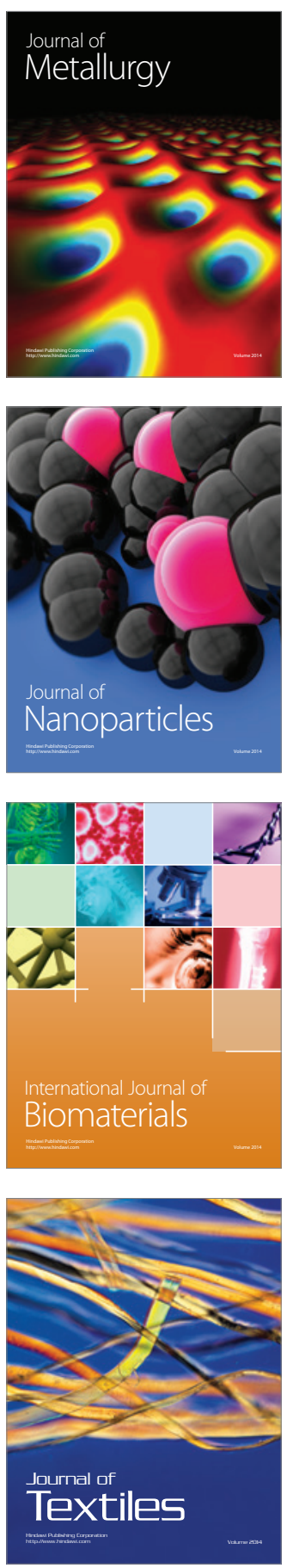